\title{
Combined atrial and arterial switch procedure for congenital corrected transposition with ventricular septal defect
}

\author{
Oliver Stümper, John G C Wright, Jo V De Giovanni, Eric D Silove, Bạbulal Sethia, \\ William J Brawn
}

\begin{abstract}
Objectives-A combined atrial and arterial switch procedure was performed in selected patients with congenitally corrected transposition to establish the morphological left ventricle as the systemic ventricle. Immediate and early follow up results are presented.

Background-Progressive right ventricular dysfunction and tricuspid regurgitation are common in patients with congenitally corrected transposition who undergo repair of associated lesions. A surgical procedure which re-establishes the left ventricle as the systemic ventricle should improve functional results.

Methods-Four symptomatic children aged from 9 months to 3 years 1 month (mean 2 years 3 months) with congenitally corrected transposition and ventricular septal defect underwent both an atrial and arterial switch procedure and were followed up for a mean of 12 months (range 6-21 months).

Results-There were no early or late deaths. Conduction abnormalities worsened in two patients. Hospital stay ranged from 8 to 17 days (mean 13 days). The cardiothoracic ratio decreased from a mean (range) of $0.65(0.6$ to 0.71$)$ to 0.58 $(0.52$ to 0.6$)$. Currently, three patients are in functional class $I$ and one child is in functional class II.

Conclusions-The combination of an atrial and an arterial switch procedure in symptomatic children with congenitally corrected transposition establishes the left ventricle as the systemic ventricle. The initial experience is encouraging with excellent immediate and early follow up results.
\end{abstract}

(Br Heart f 1995;73:479-482)

Keywords: congenital heart defects; corrected transposition; paediatric surgery

Late systemic (morphologically right) ventricular failure and progressive systemic atrioventricular (tricuspid) valve dysfunction are well recognised complications after surgical closure of ventricular septal defects in patients with congenitally corrected transposition of the great arteries. ${ }^{1-4}$ In a recent study $34.5 \%$ patients had these lesions after operation. ${ }^{5}$

The morphological right ventricle and the tricuspid valve give limited support to the systemic circulation, so that a surgical correction that establishes the morphological left ventricle as the systemic ventricle should be beneficial.

This study describes the immediate and intermediate postoperative results in four symptomatic children who had a combined atrial and arterial switch (double switch) procedure for congenitally corrected transposition and ventricular septal defect.

\section{Patients and methods}

PATIENTS

Between November 1991 and July 1993 four children (cases 1 to 4 ) with congenitally corrected transposition and ventricular septal defect underwent a combined atrial and arterial switch procedure (table 1). Their age at operation ranged from 9 months to 3 years 1 month (mean age 2 years 3 months).

Previous surgical procedures had been performed in three cases. These had all required initial pulmonary artery banding at two days to six weeks of life for cardiac failure caused by excessive pulmonary blood flow. One of these (case 1) had undergone subclavian flap repair for severe coarctation at the same time. Patient 2 had only mildly increased pulmonary blood flow caused by left ventricular outflow obstruction.

\section{INDICATION FOR OPERATION}

Two patients (cases 1 and 2) were in severe heart failure caused by severe tricuspid regurgitation before the double switch procedure. In patient 1 there was classic Ebstein's

Table 1 Data on patients

\begin{tabular}{lllll}
\hline Case & Sex & Age & Previous surgery & $\begin{array}{l}\text { Associated } \\
\text { lesions }\end{array}$ \\
\hline 1 & $\mathrm{M}$ & $2 \cdot 4$ & PA band, CoA repair & $\begin{array}{l}\text { Ebstein TV, } \\
\text { moderate TR } \\
\text { LVTO, severe } \\
\text { TR, 2nd VSD }\end{array}$ \\
2 & $\mathrm{M}$ & $0 \cdot 8$ & - & $\begin{array}{l}\text { LVOTO, severe } \\
\text { TR }\end{array}$ \\
3 & $\mathrm{M}$ & $2 \cdot 4$ & $\begin{array}{l}\text { PA band, VSD } \\
\text { closure }\end{array}$ & RVOTO \\
4 & $\mathrm{M}$ & $3 \cdot 1$ & PA band & \\
\hline
\end{tabular}

CoA, coarctatation of the aorta; LVOTO, left ventricular outflow obstruction; PA, pulmonary artery; RVOTO, right ven-
tricular outflow obstruction; TR, tricuspid regurgitation; TV, tricuspid valve; VSD, ventricular septal defect. 
malformation of the tricuspid valve. The other patient had a severely dysplastic tricuspid valve without apical displacement of the septal leaflet.

Patient 3 had undergone debanding of the pulmonary artery and closure of the ventricular septal defect at two years of age. He developed severe progressive right ventricular failure developed shortly thereafter. Five months later he underwent repeat pulmonary artery banding to prepare his left ventricle to support systemic pressures. $\mathrm{He}$ remained dependent on assisted ventilation and underwent double switch procedure eight days later. At cardiac catheterisation before operation the left ventricular pressures were $70 \%$ of the arterial pressure.

Patient 4 presented for double switch procedure at 3 years 1 month of age because of increasing cyanosis and breathlessness associated with tight banding of the pulmonary artery and considerable obstruction of the right ventricular (subaortic) outflow tract.

\section{PREOPERATIVE EVALUATION}

All patients underwent detailed preoperative ultrasound examination, electrocardiogram, cardiac catheterisation, and angiocardiography. All patients had situs solitus and levocardia. One patient (case 2) had two ventricular septal defects. Two patients had left ventricular outflow tract obstruction; this was caused by aneurysmal bulging of the ventricular septum in one (case 3 ) and associated excessive mitral valve tissue and a discrete membrane within the left ventricular outflow tract in the other (case 2). Patient 4 had significant muscular right ventricular outflow obstruction with a gradient of $45 \mathrm{~mm} \mathrm{Hg}$ at cardiac catheterisation. The aortic valve was placed anteriorly and slightly to the left in all four. Coronary artery anatomy was appropriate in all cases, with the left coronary artery arising from the right (posterior) facing sinus. No patient had single origin of the coronary arteries.

\section{SURGERY}

Surgical correction was performed on cardiopulmonary bypass with hypothermia $\left(20-22^{\circ} \mathrm{C}\right)$ and cold cardioplegic arrest. Periods of total circulatory arrest were used during various stages of the procedure.

When the anatomy was carefully inspected with the patient on bypass, the final decision to proceed to double switch procedure was taken. In both patients who had associated left ventricular outflow tract obstruction we thought that surgical correction was possible without insertion of a ventriculoarterial con-

Table 2 Surgical dato

\begin{tabular}{|c|c|c|c|c|c|c|}
\hline \multirow[b]{2}{*}{ Case } & \multirow[b]{2}{*}{ VSD closure (route) } & \multirow{2}{*}{$\begin{array}{l}\text { Bypass time } \\
\text { (min) }\end{array}$} & \multirow{2}{*}{$\underset{(\text { min })}{X \text { clamp time }}$} & \multirow{2}{*}{$\begin{array}{l}\text { Arrest time } \\
\text { (min) }\end{array}$} & \multicolumn{2}{|c|}{ Hospital stay (days) } \\
\hline & & & & & $I C U$ & Total \\
\hline $\begin{array}{l}1 \\
2\end{array}$ & $\begin{array}{l}\text { Pulmonary valve } \\
1 \text { Aortic valve } \\
1 \text { Mitral valve }\end{array}$ & $\begin{array}{l}194 \\
169\end{array}$ & $\begin{array}{l}141 \\
135\end{array}$ & $\begin{array}{l}37 \\
40\end{array}$ & $\begin{array}{l}2 \\
8\end{array}$ & $\begin{array}{r}9 \\
17\end{array}$ \\
\hline $\begin{array}{l}3 \\
4\end{array}$ & $\begin{array}{l}\text { Mitral valve } \\
\text { Mitral valve }\end{array}$ & $\begin{array}{l}160 \\
145\end{array}$ & $\begin{array}{l}125 \\
138\end{array}$ & $\begin{array}{l}23 \\
50\end{array}$ & $\begin{array}{l}5 \\
1\end{array}$ & $\begin{array}{r}17 \\
8\end{array}$ \\
\hline
\end{tabular}

ICU, intensive care unit; $\mathrm{X}$ clamp, aortic cross clamp. duit. Obstruction of the right ventricular outflow tract in patient 4 was relieved by resection of the infundibular muscle bundles. Tricuspid valve reconstruction was deemed to be necessary in only one patient (case 3), who underwent an annuloplasty. The ventricular septal defect was closed either through the mitral valve or one of the arterial valves (table 2). The arterial switch procedure was carried out in a standard fashion with the Lecompte manoeuvre and pericardial patch augmentation of the pulmonary artery in all patients. Coronary translocation was accomplished in all cases without difficulty. We noted, however, that the distance between the ostia of the coronary arteries and the sites of reimplantation was greater in patients with congenital corrected transposition than in those with simple transposition. We used a standard Senning procedure for the atrial switch. Permanent epicardial pacing wires were left at the time of operation in two patients who had either intermittent or permanent complete heart block before operation.

Total cardiopulmonary bypass times ranged from 145 to 194 minutes (mean 167 minutes) (table 2). Total cross clamp times were 125 to 141 minutes (mean 135 minutes) and circulatory arrest times ranged from 23 to 50 minutes (mean 38 minutes).

\section{FOLLOW UP}

All patients underwent close postoperative monitoring, which included repeat transthoracic ultrasound studies to assess right and left ventricular function. Because of the position and orientation of the morphological left ventricle in this condition, it was not feasible to obtain standard reproducible cross sectional images. Thus the calculation of indices for fractional shortening and ejection fraction was not deemed to be reliable. Instead an attempt was made to visualise the ventricle in its largest dimension from either subcostal or four chamber scan positions, and left ventricular areas were measured on-line both at end systole and end diastole. Left ventricular area changes were calculated according to the formula:

Area change $(\%)=[($ diastolic area - systolic area): diastolic area] $\times 100 \%$

Transoesophageal ultrasound studies were carried out in two patients with suspected baffle obstruction. Patients were followed up for 6-21 months (mean 12 months). All had detailed clinical investigations, electrocardiogram, detailed transthoracic ultrasound studies and chest $x$ ray. Two patients underwent postoperative cardiac catheterisation and angiocardiography.

\section{Results}

There were no early or late deaths. The postoperative stay in the intensive care unit ranged from one to eight days with a mean of four days. Mechanical ventilation was required for 1-6 days postoperatively (mean 3.2 days). No patient had renal or hepatic 
Figure 1 Changes in left ventricular area (diastolic area - systolic areal diastolic area) after operation in four patients.

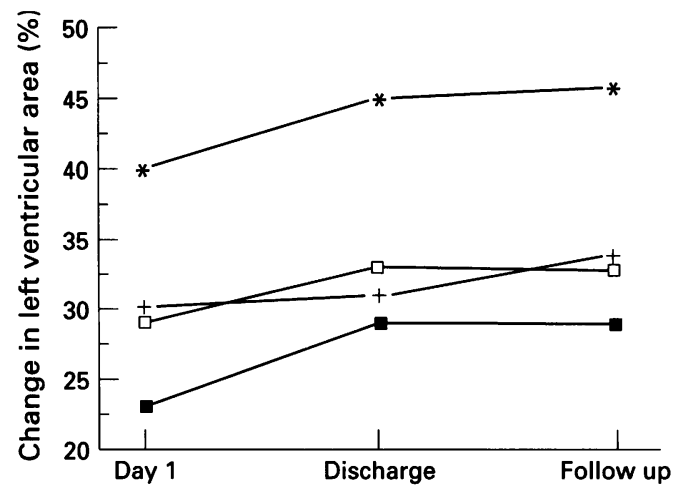

failure, or neurological deficits. Total hospital stay ranged from eight to 17 days (mean 13 days) (table 2).

In two patients conduction abnormalities progressed. Patient 1 was in intermittent third degree atrioventricular block before operation and permanent complete block developed intraoperatively. A permanent epicardial wire was placed during surgery and a permanent pacemaker system was implanted on the seventh postoperative day. Patient 3 developed right bundle branch block during surgery but had entirely normal atrioventricular conduction.

Serial transthoracic ultrasound showed improvement of left ventricular function in the early postoperative period, which was maintained after hospital discharge. The calculated left ventricular area change ranged from $23 \%$ to $40 \%$ (mean $30.5 \%$ ) on the second postoperative day, from $29 \%$ to $45 \%$ (mean $32 \%$ ) at hospital discharge, and $29 \%$ to $46 \%$ (mean $35.5 \%$ ) at last follow up (fig 1 ). Transthoracic ultrasound studies suggested residual haemodynamic abnormalities in two patients (cases 2 and 3), who subsequently underwent cardiac catheterisation. There was obstruction of the superior vena cava in both; however, mean withdrawal gradients were low ( 3 and $4 \mathrm{~mm} \mathrm{Hg}$ respectively) and baffle dilatations were not performed. Patient 3 was also found to have mild pulmonary artery obstruction (gradient $13 \mathrm{~mm} \mathrm{Hg}$ ) and mild central aortic regurgitation.

Serial chest $x$ rays in the early postoperative period showed a rapid decrease in pulmonary oedema, which had been present in three patients before operation (cases 1-3). There was also a considerable decrease in the

Figure 2 Changes in cardiothoracic ratio as assessed by chest $x$ rays before and after operation in four patients. cardiothoracic ratio in all patients, which continued during the follow up period (figs 2 and 3 ). The cardiothoracic ratio ranged from 0.6 to 0.71 (mean 0.65 ) preoperatively, from 0.59 to 0.64 (mean 0.61 ) at hospital discharge, and from 0.51 and 0.58 (mean 0.56 ) at last follow up.

At 6-21 months postoperatively all four patients are alive and well. Three are in functional class $I$ and on no medication. One patient (case 3 ) is in functional class II and is on continued medication.

\section{Discussion}

Closure of a ventricular septal defect is the most common procedure in patients with congenitally corrected transposition. The immediate and long-term results have improved over the past decade, however, the long-term function of the morphological right ventricle as a systemic ventricle continues to cause concern. In a recent study by Colli $e t a l^{5}$ over a third of patients $(34.5 \%)$ had right ventricular dysfunction postoperatively. Earlier studies suggested that progressive tricuspid regurgitation and the development of complete atrioventricular block may contribute to late right ventricular failure..$^{2-4}$

The combination of an atrial and an arterial switch procedure establishes the morphological left ventricle as the systemic ventricle in patients with congenitally corrected transposition. The excellent results of the arterial switch procedure in infants with complete transposition make such an approach feasible in selected children with congenitally corrected transposition. ${ }^{67}$

Ilbawi et al first reported a surgical correction that established the left ventricle as the systemic ventricle in patients with congenitally corrected transposition. ${ }^{8}$ They performed a combined Senning and Rastelli procedure in a child with corrected transposition, ventricular septal defect, and pulmonary atresia. Very recently Yagihara and colleagues $^{9}$ have reported their surgical results in 10 children with corrected transposition. Two had a combined atrial and arterial switch procedure and eight children had an atrial switch and a Rastelli procedure. There were three early and late deaths.

In our series of four children with congenitally corrected transposition and ventricular septal defect preoperative right and left ventricular pressures were identical in three patients and $70 \%$ of systemic in patient 3 . Two of our patients had subpulmonary obstruction, caused by a combination of a discrete fibromuscular membrane in one and a combination of accessory mitral valve tissue and a rightward shift of the ventricular septum in the other. Detailed preoperative evaluation by both transthoracic and transoesophageal ultrasound delineated the exact morphology, which was subsequently confirmed during surgical inspection. In both the double switch procedure was performed successfully with no significant residual gradient on follow up. The finding of right ventricular 

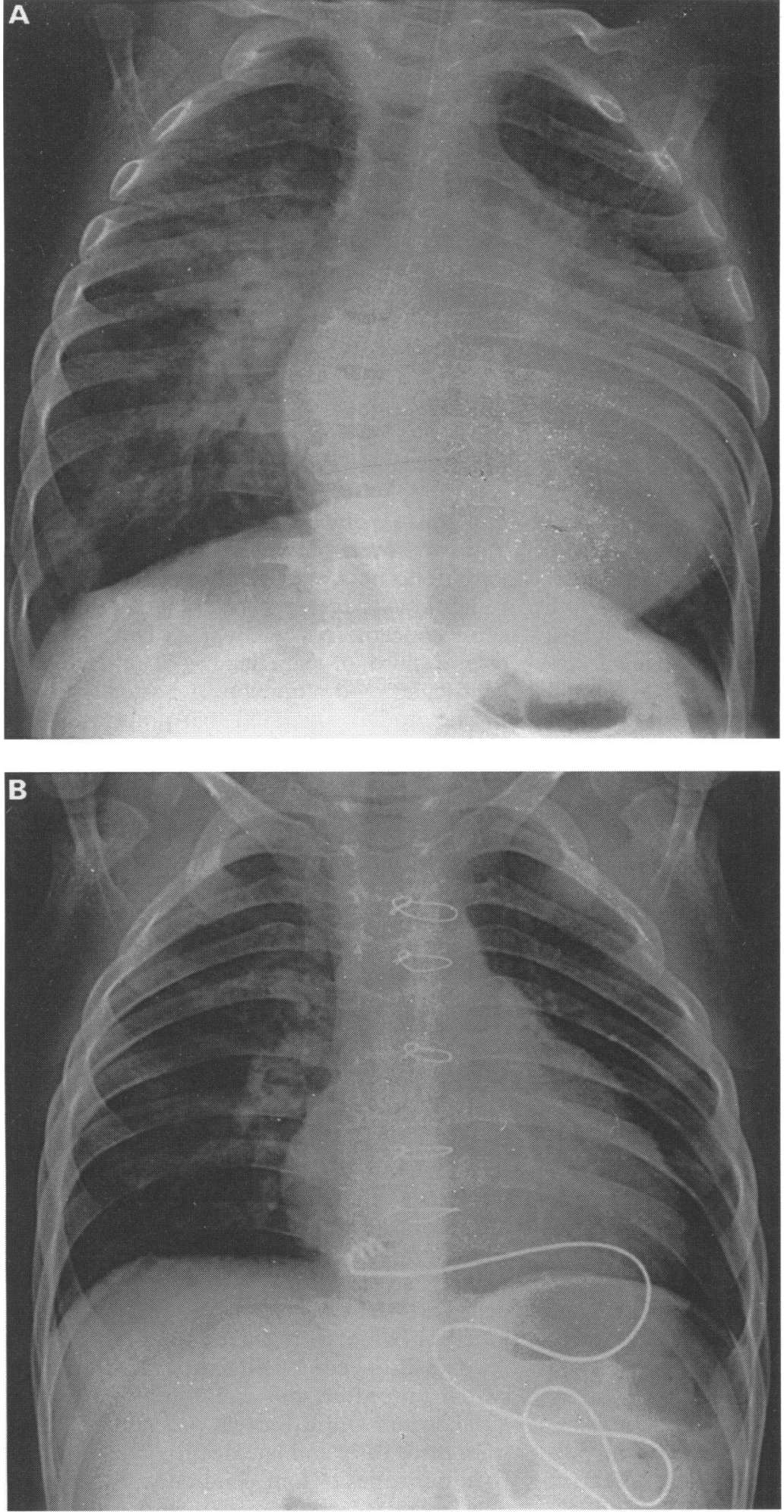

Figure 3 Chest $x$ rays of patient 1 before $(A)$ operation and 8 months postoperatively (B). (subaortic) outflow obstruction in patients with congenitally corrected transposition is rare. In one of our patients obstruction was relieved by resection of hypertrophied muscle bundles.

Tricuspid valve regurgitation, a frequent preoperative finding, seems to be caused by a combination of annular dilatation and a high incidence of morphological abnormalities. ${ }^{10}$ It is a major factor in progressive right ventricular dysfunction after conventional surgical repair. After the double switch procedure the mitral valve is re-established as the systemic atrioventricular valve. With the tricuspid valve remaining in the low pressure pulmonary circulation the need for tricuspid valve reconstruction or replacement is limited, and the increased risk during conventional surgical correction may be avoided. ${ }^{14}$ In the present series three children had moderate to severe tricuspid regurgitation preoperatively. Tricuspid annuloplasty was deemed to be indicated at the time of the double switch procedure in only one. No patient had either tricuspid or mitral valve regurgitation at the latest follow up.

The initial results of this series suggest that a combined atrial and arterial switch procedure can result in physiological correction with low mortality in selected patients with congenitally corrected transposition.

1 Metcalfe J, Somerville J. Surgical repair of lesions with , 50:476-82.

2 Graham TP, Parrish MD, Boucek RJ, et al. Assessment of ventricular size and function in congenitally corrected ventricular size and function in congenitally corrected
transposition of the great arteries. Am $\mathcal{f}$ Cardiol 1983; 51:245-51.

3 Westerman GR, Lang P, Castaneda AR, Norwood WI Corrected transposition and repair of associated intracardiac defects. Circulation 1982;66(suppl I):197-202.

4 Fox LS, Kirklin JW, Pacifico AD, Waldo AL, Bargeron LM. Intracardiac repair of cardiac malformations with atrioventricular discordance. Circulation 1976;54:123-8.

5 Colli AM, Freed MD, Lock JE, Jonas RA, Mayer JE, Castaneda A. Outcome of patients with corrected transposition. Cardiol Young 1993;3(suppl 1):152(abst).

6 Planche C, Bruniaux J, Lacour-Gayet F, et al. Switch operation for transposition of the great arteries in neonates-a study of 120 patients. $\mathcal{F}$ Thorac Cardiovasc Surg 1988;96:354-63.

7 Brawn WJ, Mee RBB. Early results for anatomic correction of transposition of the great arteries and for double outlet right ventricle with subpulmonary ventricular septal defect. $₹$ Thorac Cardiovasc Surg 1988;95:230-8.

8 thbawi MN, DeLeon SY, Backer CL, et al. An alternative approach to the surgical management of physiologically corrected transposition with ventricular septal defect and pulmonary stenosis or atresia. $\mathcal{F}$ Thorac Cardiovas Surg 1990;100:405-10.

9 Yagihara T, Kishimoto $\mathrm{H}$, Isobe $\mathrm{F}$, et al. Double switch operation in cardiac anomalies with atrioventricular and ventriculoarterial discordance. $\mathcal{F}$ Thorac Cardiovasc Surg 1994;107:351-8.

10 Allwork SP, Bentall $\mathrm{HH}$, Becker AE, et al. Congenitally ccTGA: morphologic study of 32 cases. Am $\mathcal{F}$ Cardio 1976;38:910-23 